\title{
FACEBOOK COMO FERRAMENTA DE INTERAÇÃO EXTRACLASSE PARA APRENDIZES DE LÍNGUA ESPANHOLA
}

\section{FACEBOOK AS AN INTERACTIONAL EXTRA CLASSROOM TOOL FOR SPANISH LANGUAGE LEARNERS}

\section{Hugo Jesús Correa Retamar*}

\section{RESUMO}

O artigo analisa, a partir dos textos de Riel \& Polin (2004), Hewitt (2004), Stahl (2009; 2011), Rodríguez Illera (2007), Gros Salvat (2008) e Pochon-Berger (2011), as interações ocorridas através do Facebook entre alunos do Ensino Médio de uma escola pública como apoio extraclasse à aula de Língua Espanhola. Sendo uma presença bastante frequente na vida dos alunos de hoje, principalmente no que se refere ao Ensino Médio, o Facebook tem se apresentado como uma opção possível para o ensino, visto que incorpora a vida do aluno à escola e não o contrário. Dessa forma, neste trabalho são analisadas interações ocorridas através do Facebook no ano de 2013 a partir da experiência realizada com uma turma de 18 alunos de língua espanhola em seu primeiro contato escolar com essa língua no primeiro ano do Ensino Médio. Tal reflexão sobre o uso do Facebook busca entender qual o papel dessa ferramenta para a aprendizagem da Língua Espanhola, bem como para a criação de laços maiores entre alunos e professores. As perguntas a serem respondidas são: 1) pode efetivamente o Facebook organizar uma comunidade de prática ou de construção de conhecimento para a aprendizagem de línguas? Os alunos participam do Facebook quando esse passa a fazer parte das obrigações da escola? Os alunos valorizam esse recurso e publicam por livre e espontânea vontade? Os alunos estão orientados para as atividades do Facebook em todos os momentos em que são chamados a participar? Inicialmente são revisados alguns estudos que tratam da aprendizagem em comunidades virtuais ou espaços virtuais, para logo tratar especificamente do Facebook como recurso virtual de aprendizagem de espanhol em uma comunidade.

Palavras-chave: Interação; Facebook ${ }_{i}$ Aprendizagem.

\section{ABSTRACT}

Starting from texts by from Riel and Polin (2004), Hewitt (2004), Stahl (2009; 2011), Rodríguez Illera (2007), Gros Salvat (2008) and Pochon-Berger (2011), the article reviews the interactions among high school students from a public school on Facebook as an extracurricular activity of the Spanish language class. As Social Medias are a constant presence in the lives of today's students, especially regarding teens who are in High School, Facebook has emerged as a feasible option for teaching, since it integrates the life

\footnotetext{
*Universidade Federal do Rio Grande do Sul, Porto Alegre (RS). Brasil. huretamar@gmail.com 
of the student to the school and not vice versa. Thus, this study analyzes interactions that happened on Facebook in 2013 from an experiment conducted with a group of 18 high school students of Spanish in their first contact with the foreign language during their first year. Such a reflection on the use of Facebook aims to understand the role of this tool in the learning process of the Spanish language as well as its function as a way to bring students and teachers closer. The questions to be answered are: 1) Can Facebook effectively organize a community of practice or knowledge building for language learning? Do students use Facebook when it becomes a school obligation? Do students prize this resource and do they publish on Facebook by their own free will? Are the students instructed for the Facebook activities at all times they are invited to participate? First, some studies about learning in online communities or virtual spaces are reviewed to, then, acknowledge specifically Facebook as a virtual learning resource of Spanish in a community.

Keywords: Interaction, Facebook; Learning.

\section{COMUNIDADES E APRENDIZAGEM EM CONTEXTO VIRTUAL}

Segundo Corominas (1987) a palavra comunidade vem do latim commune e communis e designaria em sua origem o conjunto das pessoas que se vinculam pelo cumprimento de obrigações comuns e recíprocas. Logo, não é ao acaso que esse termo passou, a partir do século XVIII e XIX, a designar uma "forma de agrupamento baseada na proximidade, partilha de experiências e formas de vida ou mundividências, sensibilidades e experiências" (RODRIGUEZ ILLERA, 2007, p.117).

Lave e Wenger (1991, autores igualmente presentes na discussão de Rodríguez Illera, 2007), também se preocupam com as comunidades e as relacionam à ideia de aprendizagem. Para eles, o aumento da participação de um indivíduo em uma comunidade de prática da periferia à plenitude evidencia aprendizagem. Em seu entendimento a aprendizagem se dá de forma situada, como um processo de participação que cresce gradualmente em engajamento e complexidade, à medida que os indivíduos aprendem (LAVE e WENGER, 1991). Segundo essa perspectiva, a aprendizagem implica a construção/transformação de identidades que altera o lugar do indivíduo em comunidades de prática. A partir dos autores é possível entender que se aprende em conjunto e que, ao aprender, transformam-se as relações sociais e identidades dos sujeitos, já que assumem novas funções ao demonstrarem maior engajamento nas interações sociais das quais fazem parte.

Com a era virtual, a partir do século XX, o conceito de comunidade é mais uma vez questionado e passa a designar também espaços virtuais em que pessoas com objetivos, vivências ou afinidades comuns passam a se encontrar para discutir, compartilhar e até aprender. Assim, pensando no contexto e na importância dessas novas comunidades para a aprendizagem social, autores como Riel e Polin (2004) 
identificaram seus diferentes tipos e chegaram a três classes de comunidades de aprendizagem: baseadas em tarefas; baseadas em práticas; e baseadas na construção de conhecimento. Segundo as autoras, a primeira contempla um grupo de indivíduos que se unem para resolver uma tarefa ou chegar a um produto final, uma espécie de união cooperativa na qual várias pessoas com habilidades diferentes se aliam para realizar uma tarefa comum; a segunda abarca um grupo que tem uma prática comum e deseja partilhá-la - por exemplo, em fóruns de discussão de profissionais; já a terceira, que se parece muito às anteriores, tem o compromisso de produzir conhecimento, que pode surgir da própria discussão das práticas dos envolvidos.

A importância dada às comunidades virtuais de aprendizagem lança novas luzes para a educação e nos faz refletir, como educadores, sobre quais ambientes são possíveis e efetivos para a aprendizagem, fazendo-nos pensar na dialética da aprendizagem formal, que teria lugar na escola e em sala de aula; e na aprendizagem informal - que pode se dar nos ambientes virtuais anteriormente citados. Tais ambientes de troca, e de aprendizagens, muitas vezes são criados em função dos interesses ou afinidades entre participantes, que, não raramente, sequer se conhecem face a face. Os participantes, aos quais chamaremos membros, acabam por formar uma espécie de comunidade, se pensamos no conceito discutido por Rodríguez Illera (2007).

Muitos educadores já perceberam o papel importante que cumprem os ambientes virtuais para a aprendizagem, seja pelo seu dinamismo, seja pela facilidade e rapidez do acesso à informação (confiável ou não), e, com isso, já se podem ver experiências muito exitosas que os utilizam como um recurso complementar à sala de aula, ou como uma peça importante para a construção conjunta do conhecimento e para a aprendizagem social. Atualmente temos fóruns de discussão de profissionais que compartilham suas práticas, tiram dúvidas, procuram sugestões e relatam experiências bem-sucedidas. Um exemplo, que poderia ser classificado nos moldes de Riel e Polin (2004) como uma comunidade de prática, é o fórum de discussão de professores de espanhol ELEBRASIL, do qual faço parte como professor de língua espanhola. Nesse espaço, profissionais do ensino dessa língua realizam toda a sorte de atividades descritas anteriormente, além de divulgarem eventos e congressos de língua espanhola.

Interessado nessas novas comunidades de aprendizagem, Stahl (2009) nos apresenta um estudo realizado com alunos de matemática; universitários que não se conheciam anteriormente e que se encontram através de um chat para realizar tarefas matemáticas após havê-las realizado individualmente em papel. Em tal estudo, o autor evidencia que o sucesso da resolução das tarefas em grupo foi muito superior 
à resolução individual, realizada em papel, de cada um dos indivíduos pesquisados, o que em um primeiro olhar supõe que os alunos são melhores em grupo que individualmente, e que aprenderam uns com os outros.

Stahl (2009) identificou nessas interações virtuais entre os estudantes dois comportamentos muito importantes para a construção do conhecimento em conjunto. Por um lado, o que chamou de "narrativa expositiva", que se caracteriza pela explicação, por parte de um dos membros aos demais, dos procedimentos executados por ele para chegar à resolução de uma tarefa na qual foi bem-sucedido. Por outro, o que chamou de "pesquisa exploratória", que pode ser visualizada quando os membros do grupo exploram juntos um tópico sobre o qual têm dúvidas. O texto de Stahl permite pensar no conhecimento construído a partir das interações e contribuições dos indivíduos vistos como sujeitos não individuais. Tal perspectiva vê cada contribuição dos membros (não importando se é a resposta certa ou equivocada) como uma teoria importante para a obtenção da resposta final, que depende dessas contribuições. No chat estudado por Stahl, tudo é registrado e permanece por escrito, logo, é um grande avanço para a construção do conhecimento em conjunto, já que os erros individuais serviriam para os acertos coletivos. Tal ideia propicia pensar que o conhecimento desenvolvido em grupo se refere também à própria capacidade de trabalhar em grupo. Se o indivíduo a desenvolve, ele a levará a outro grupo, e se é capaz de levar essa experiência a outro contexto, ela foi aprendida.

Nesse mesmo estudo, o autor aponta que muitas das plataformas virtuais que têm como fim a aprendizagem não foram pensadas para o conhecimento conjunto, e sim para a cognição individual e para a transferência de representações de conteúdos mentais. $\mathrm{O}$ autor finaliza seu texto apontando ainda alguns recursos que deveriam ser considerados pelos criadores de plataformas de aprendizagem em conjunto, entre eles estariam: persistência e visibilidade; referenciação dêitica espaços virtuais; espaços pessoais e compartilhados; suporte computacional, acesso a ferramentas e recursos; possibilidade de abertura novos espaços e (sub) comunidades; permissão às sutilezas de linguagem natural. Atualmente, muitos desses recursos já estão presentes em redes sociais populares como veremos mais adiante. Poderiam elas atuar como comunidades de aprendizagem?

Em 2011, Stahl traz contribuições para a análise da fala-em-interação, a partir da criação de uma espécie de equivalência entre seus princípios e a interação via chat. Dessa vez, o autor analisa um grupo de estudantes que resolvem problemas matemáticos a partir de um chat em um trabalho colaborativo. $\mathrm{O}$ encontro virtual dos estudantes tem o apoio de um monitor para assuntos técnicos, que os estimula a 
realizar determinados procedimentos quanto ao funcionamento do chat. Além disso, os estudantes podem abandonar a conversa quando assim o desejarem, como ocorre normalmente em redes sociais, buscando certa naturalidade para a aprendizagem, ao tirá-la dos horários rígidos de uma sala de aula, por exemplo.

Através das interações via chat exploradas por Stahl (2011), é possível perceber o papel de incentivo de um membro a outro para a realização das tarefas, bem como a desistência de outros, que poderiam ter acesso às descobertas de seus colegas por meio de explicações de equações em uma wiki, explicação formulada pelos membros que a resolveram. Mais uma vez, fica evidente, no texto desse autor, que a aprendizagem não diz respeito apenas ao conteúdo, mas também à capacidade de interagir em grupos, de colaborar.

Os estudos de Stahl $(2009$; 2011) são muito importantes para a legitimação das comunidades virtuais como ambientes de aprendizagem, bem como o fórum de professores mencionado, mas ambos se direcionam a jovens universitários ou a profissionais. Cabem, então, as questões: É possível tratar de comunidades virtuais na escola regular com estudantes do Ensino Médio? É possível criar espaços virtuais que apoiem ou dinamizem a sala de aula na Educação Básica?

\section{PLATAFORMAS VIRTUAIS EM CONTEXTO ESCOLAR}

Já em contexto escolar, Hewitt (2004) analisa interações entre um grupo de alunos da escola regular visando à construção do conhecimento através de uma plataforma criada para esse fim, uma espécie de Fórum, o KBC ${ }^{1}$. O trabalho com o $\mathrm{KBC}$ requeria uma série de procedimentos sistemáticos, controlados pelo professor. Inicialmente, os alunos deviam escolher, a partir de uma série de temas propostos dentro de um conteúdo - no caso, o da Biologia -, algum tipo de problema a ser solucionado por meio de pesquisas, discussões e de sua publicação em etiquetas criadas na plataforma. As etiquetas existentes determinavam o tipo de participação do aluno, e entre elas estavam: My theory, New Information, I need to understand. As publicações dos alunos eram controladas pelo professor, não quanto ao conteúdo, ou seja, se uma teoria desenvolvida para explicar o fenômeno estudado estava certa ou errada, mas quanto à pertinência dela à etiqueta correspondente. O professor, aquele que controlava as publicações, atuava como problematizador das teorias dos alunos e acabava por trazer o desequilíbrio às certezas dos estudantes, o que

1 Knowledge Building Community 
acabou por motivá-los a buscarem mais informações e a refletirem sobre o papel da teoria, não mais vista como certeza absoluta. A experiência, que se assemelhava a um projeto de pesquisa na escola, era acompanhada de encontros presenciais sistemáticos com o professor, uma espécie de orientador.

$\mathrm{O}$ KBC pareceu ser uma excelente ferramenta para a construção não apenas do conhecimento em biologia, mas também para o desenvolvimento da aprendizagem em conjunto e para a legitimação do discurso do aluno, já que era ele quem deveria postar a "sua teoria" para a explicação dos fenômenos por meio das leituras realizadas, das interações com os demais colegas e com o professor, e das considerações que emanaram de todos esses procedimentos. A experiência exitosa era uma tarefa escolar com acompanhamento diário sistemático do professor, fosse ele virtual ou presencial. Contudo, o que fazer quando a escola não possui uma plataforma tão organizada ou um momento de acompanhamento como o do exemplo de Hewitt?

\section{COMUNIDADES VIRTUAIS, CONTEXTO ESCOLAR E LÍNGUA ESPANHOLA}

Sempre acreditando no potencial do espaço virtual para a aprendizagem e tendo um espaço muito reduzido de encontro com estudantes do Ensino Médio de uma escola pública - 90 minutos semanais -, antes mesmo da leitura das experiências relatadas por Hewitt $(2004)$ e Stahl $(2009 ; 2011)$, comecei a utilizar páginas do tipo wiki com meus estudantes de língua espanhola, com o objetivo de dinamizar e multiplicar o acesso dos estudantes ao contato com a língua a ser aprendida e possibilitar que a aprendizagem social se estabelecesse entre aquela comunidade de estudantes com vivências comuns e compartilhadas. As páginas buscavam, além do trabalho extraclasse em língua espanhola, criar laços identitários para aquela comunidade de alunos (ver Retamar, 2011).

Nas páginas criadas por mim eram publicadas tarefas, textos, resumos, materiais auditivos, vídeos, além das próprias produções dos alunos. Cada aluno tinha seu usuário e sua senha e podia publicar os conteúdos em sua página wiki, que estava vinculada à página central administrada por mim, o professor. As páginas eram cheias de imagens e cores para chamar a atenção visual dos jovens, porém, por mais que as achassem interessantes e as elogiassem, as publicações dos estudantes eram escassas, muitas delas só ocorriam em sala de aula, ou após muita insistência de minha parte. Os estudantes, pelo pouco acesso à página fora de sala de aula, constantemente perdiam sua senha de acesso e, com isso, a fluência do trabalho 
ficava comprometida, já que a wiki não fazia parte da vida do estudante, tornando-se mais uma das obrigações da escola. Logo, a experiência de dois anos com páginas wiki $(2011,2012)$ não gerou os frutos esperados, talvez porque os laços da comunidade com esse ambiente virtual não fossem tão motivadores ou profundos, ou pela falta de sistematicidade de suas ferramentas que, à diferença do KBC de Hewitt (2004), não possuíam etiquetas ou não eram um trabalho diário dos estudantes. Dessa forma, tornou-se necessário pensar em uma comunidade que não fosse um esforço para os discentes ou que não fosse alheia às suas vidas. Foi então que um aluno sugeriu: Por que não o Facebook?

Os estudantes já utilizavam o Facebook em sua vida cotidiana, todos estavam no Ensino Médio, e a rede em questão possuía e possui uma série de recursos, entre eles a criação de grupos secretos, que poderiam ser utilizados em sala de aula ou fora dela. Se revisarmos os conselhos de Stahl (2009) para a criação de plataformas virtuais de aprendizagem em conjunto, percebemos que muitas das anotações do autor já se fazem presentes no Facebook, entre elas podemos citar: persistência e visibilidade - é possível criar grupos abertos ou fechados no Facebook com recursos diferentes das páginas pessoais dos usuários; referenciação dêitica - é possível fazer a busca de palavras em um grupo do Facebook, a busca mostrará todas as vezes que a palavra foi usada em uma publicação; espaços virtuais; espaços pessoais e compartilhados - podemos ver aqui a página pessoal do usuário que está vinculada à página do grupo no Facebook; suporte computacional, acesso a ferramentas e recursos - nos grupos do Facebook é possível postar arquivos de texto (PDF, Word, PowerPoint), imagens, vídeos, além de saber quantas e quais pessoas do grupo visualizaram os arquivos e publicações, o que não ocorre em uma página pessoal na mesma rede; possibilidade de abertura de novos espaços e (sub)comunidades; permissão às sutilezas de linguagem natural - talvez um dos recursos mais importantes para o contexto do trabalho com adolescentes, e a criação de um espaço formal informal de aprendizagem. Além desses pontos, é importante ressaltar ainda a familiaridade dos jovens com a rede social e o sentimento de pertença promovido pela mesma, o que reforça os vínculos da comunidade estabelecida, diferente do que ocorria com as páginas wiki. Então, por que não tentar?

\section{FACEBOOK COMO APOIO À AULA DE ESPANHOL}

Para a transição das páginas wiki ao Facebook, encontrei dois argumentos importantes: 1) o controle dos acessos que é possível ter na rede; 2) os alunos 
já serem usuários do Facebook, o que faria com que problemas como a perda de suas senhas e seus usuários não voltassem a acontecer, pois a rede já fazia parte da vida daqueles alunos e não seria uma novidade inventada pela escola. Mas será que o Facebook poderia ser um recurso didático tão bem-sucedido quanto o que li nos relatos de Hewitt (2004)? Seria o Facebook capaz de organizar uma comunidade de aprendizagem de língua espanhola?

No início de 2013, meu primeiro ano com esses estudantes que começavam a ter aulas de língua espanhola no primeiro ano do Ensino $\mathrm{Médio}^{2}$, fiz a sugestão de criarmos um grupo no Facebook chamado español 1, após a experiência já relatada com outros estudantes em 2012. Tal sugestão, aceita pelos alunos, só foi tornada efetiva após certificar-me de que todos os dezoito alunos da turma já possuíam um Facebook pessoal. O grupo virtual, que prefiro chamar de comunidade, já que estreita os laços entre estudantes que compartilhavam uma série de vivências, serviria de apoio às aulas de língua que ocorriam duas vezes na semana com 45 minutos de duração cada aula. Usaríamos o grupo/comunidade para lembrar de tarefas a serem entregues, publicar materiais interessantes em espanhol, realizar tarefas, fazer consultas sobre dúvidas, ou seja, para atitudes comuns a quem está interessado em aprender, no nosso caso: língua espanhola.

Acordamos ainda no primeiro encontro que as publicações no grupo/ comunidade seriam feitas em língua espanhola, e que antes de publicar os alunos poderiam consultar o livro texto, ou mesmo a Internet. Chegamos à conclusão de que, por mais que alguém não soubesse escrever algo em espanhol, todos aprenderiam em conjunto, já que as publicações ficariam visíveis a todos e, como vemos em Stahl $(2009 ;$; 2011) e Hewitt (2004), até os equívocos são passos fundamentais para a construção conjunta do conhecimento. As correções das tarefas ocorreriam em mensagem privada, recurso do Facebook, se o aluno não quisesse ficar exposto diante dos demais, o que realmente foi feito na prática.

Nas primeiras aulas de língua espanhola, os 18 estudantes aprenderiam a cumprimentar, a apresentar-se em espanhol, a falar um pouco de si mesmos e, nesse contexto, surgiu a oportunidade de inaugurarmos nosso grupo/comunidade virtual, afinal, nada mais corriqueiro em uma rede que se apresentar por escrito. Em aula realizamos algumas tarefas preparatórias e fizemos a leitura de pequenos textos de apresentações virtuais em espanhol trazidos por mim. Em casa os alunos deveriam publicar suas apresentações no grupo español 1. Cada aluno escolheria um

$2 \mathrm{Na}$ escola analisada, os alunos optam pela língua que estudarão em todo o Ensino Médio, logo a escolha pela língua espanhola já põe os estudantes em certo grau de afinidade, o que contribui para a categorização do grupo como uma comunidade. 
modelo e falaria aquilo que julgasse interessante sobre si mesmo. No excerto $1^{3}$, abaixo, disponho algumas das apresentações publicadas no grupo. As mensagens estão dispostas tal como apareceram e as correções foram feitas individualmente a cada aluno por mensagem privada como consta em negrito. Podemos notar ainda que todas as publicações foram vistas por todos os alunos (após cada publicação o próprio Facebook avisa: vista por todos). As mensagens aparecem na ordem de publicação, como podemos ver pela data:

\section{Excerto 1: Presentación}

Alumno $^{4}$ 1: Presentación: Hola. Me llamo Joaquín, tengo 13 años, vivo en Porto Alegre, pero soy de Cabanha. Estudo en aquí hasta los 3 años y yo prefiro animales lo que las personas.

2 de mayo de 2013 a la(s) 20:48

Vista por todos

Profesor: Corregido por mensaje

Alumno 2: Hola. Me llamo María y tengo quince años. Soy brasileña y vivo en Porto Alegre. Yo soy estudiante del Colegio, pero estudié en el Colegio Anita. A mí me gusta los animales, especialmente los perros.

2 de mayo de 2013 a la(s) 21:28

Vista por todos

Profesor: corregido por mensaje

Alumno 3: Hola. Me llamo Pedro, tengo 17 años, vivo en Guaíra, pero soy de Porto Alegre. Estudo en Colégio hasta los 4 años y yo prefiro las personas.

2 de mayo de 2013 a la(s) 21:39

Vista por todos

Profesor: corregido por mensaje

Alumno 4: Hola. Me llamo Juana, mi apellido es Martínez, tengo catorce años. Naci en Porto Alegre, pero vivo en Jacinto. Es mi primero año en Colegio, pero estudié en Marista. Tengo dos hermanos, un chico y una chica.

2 de mayo de 2013 a la(s) 21:58

Vista por todos

Profesor: corregido por mensaje

Alumno 5: Hola, me llamo Marcus, soy brasileña y vivo en Porto Alegre. Tengo catorce años. Soy estudiante del Colegió, és myo quinto año

3 Os nomes dos alunos, bem como de suas cidades e escolas de origem foram substituídos por pseudônimos para preservar as suas identidades.

4 Optei por manter o nome "alumno"/ "profesor;" (em espanhol) ao invés de aluno/professor (em português) nos excertos, diferentemente do que ocorre no corpo do artigo 
en el colegió. Tengo dos hermanas. Brasil és un país muy alegre, és él país del fútbol. Sí alguien está interesado en hablar conmigo, mándame un correo.

2 de mayo de 2013 a la(s) 22:31

Vista por todos

Profesor: corregido por mensaje

Alumno 6: Hola, me llamo Antonio, soy brasileño y vivo en Porto Alegre. Tengo catorce años. Soy estudiante del Colegió,és myo tercero año en el colegió. Tengo un hermano e una hermana, más viejo. Tengo dos perros, Olivio e Tiny.

2 de mayo de 2013 a la(s) 22:55 cerca de Porto Alegre

Vista por todos

Profesor: corregido por mensaje

Alumno 7: Tardó, pero publicado.

Hola, me llamo Juan, soy brasileño y vivo en Porto Alegre. Tengo quince años. Soy estudiante del Colegió. Vivo com my madre e my padre. Me gusta jugar Baloncesto y Voleibol.

4 de mayo de 2013 a la(s) 14:26 cerca de Porto Alegre

Vista por todos

Professor: corregido por mensaje

Alumno 8: Maestro, Yo estoy mucho enferma por lo tanto yo no pude enviar martes, miércoles, jueves y viernes. Pero ahora estoy mejor entonces... Presentación:

Hola, me llamo Sonia y tengo catorce años. Soy brasileña y vivo en Jacinto. Tengo dos hermanas, Alana e Anitaa. Soy estudiante del Colégio y es mi quinto año en esta escuela, pero hasta el cuarto grado yo estudié en el Santa. Tengo dos perros, Deco y Guriza. Yo amo animes, por ejemplo, "Hotarubi no Mori e", "Kaichou wa Maid-sama!", Nana", "Kaleido Star" y "Ano Hi Mita Hana no Namae wo Bokutachi wa Mada Shiranai." mejor conocido como Ano Hana, (Yo lloré mucho en todos ellos).

4 de mayo de 2013 a la(s) 20:15

Vista por todos

Profesor: iQué te mejores!

Profesor: corregido por mensaje

Alumno 9: Hola. Me llamo Gustavo, soy brasileño y tengo cuatorce años, soy estudiante de colegio. Tengo un hermano, yo vivo en Jacinto y si alguien 
está interesado a hablar conmigo, mándame um

coreio.

6 de mayo de 2013 a la(s) 17:54

Vista por todos

Profesor: corregido por mensaje

Como notamos, os alunos que publicaram, consultaram a publicação do colega anterior, visto que não havia uma direção fechada de que dados deveriam constar na apresentação. Cada aluno postou aquilo que achava interessante sobre si e ao mesmo tempo interagiu com o colega que publicou antes dele, reforçando os laços da comunidade e o espírito de grupo. Podemos verificar tal observação se comparamos as publicações dos alunos 1, 2 e 3 . A aluna 1, primeira a publicar, mencionou sua afeição aos animais, o que foi importante para a aluna 2, que também fez essa observação. O aluno 3, por sua vez, ainda que não houvesse perguntas relativas à sua preferência entre animais ou pessoas, decidiu responder às outras alunas dizendo que preferia pessoas. A frase fica sem sentido se a analisamos separadamente, sem considerar os dois depoimentos anteriores, mas, no contato com as apresentações de 1 e 2, entendemos que o aluno 3 está respondendo a uma espécie de provocação feita por elas ao manifestarem que preferem animais a pessoas. Já a aluna 4 decidiu falar das experiências escolares anteriores, como os demais, e optou também por falar de sua família. $\mathrm{O}$ aluno 5 apresentou inclusive algo de seu país, como se falasse com estrangeiros - para ele foi relevante falar do Brasil, país onde mora, em uma apresentação. $\mathrm{O}$ aluno 6 falou de seus gostos pessoais, e os alunos 7 e 8 inicialmente se desculparam pela demora de suas publicações, o que pode ser visto pela diferença de datas em relação aos demais. A aluna 8 deu um panorama de suas atividades preferidas com experiências muito pessoais, enquanto o aluno 9 voltou a uma apresentação simples. Como referido, todas as apresentações foram corrigidas por mim por mensagem privada e retomadas em sala de aula. A atividade cumpriu com seus objetivos, já que promoveu a participação e a interação do grupo em língua espanhola, e a comunidade virtual foi inaugurada.

Em outra ocasião, para trabalhar o vocabulário das profissões, sugeri que os alunos trouxessem de casa a roupa do profissional que gostariam de ser no futuro. Em aula vestiram essas roupas e procuraram o nome da profissão em espanhol. O nome foi copiado em uma etiqueta colada na fantasia do aluno e cada um deles foi fotografado individualmente por mim. As fotografias foram postadas no grupo virtual secreto e posteriormente cada aluno deveria publicar, em casa, a rotina de um dia desse profissional. Novamente as correções foram feitas por mensagem privada. Antes dessa atividade, em aula, foram trabalhadas as horas, dias da semana, verbos de rotina e foi publicado um vídeo em espanhol de cada conteúdo no grupo. 
Tais materiais serviram de referência para a escrita do dia do profissional pelo aluno. Contudo, ainda que todos estivessem muito envolvidos na atividade, tive que, como professor, motivar os alunos a publicarem suas rotinas, já que muitos esqueciam e só lembravam quando estavam em aula. Tal papel de membro motivador também esteve presente nos artigos de Stahl (2011) e Hewitt (2004). No primeiro autor, as provocações ou incentivos foram desencadeados por monitores ou pelos próprios estudantes e, no segundo, pelo professor orientador e pelos próprios alunos por meio das etiquetas de publicação.

No decorrer do ano, o grupo virtual español 1 passou a ser uma espécie de comunicação, formal e informal ao mesmo tempo, daquela comunidade de 19 pessoas, contando o professor. Houve um espaço grande para as "sutilezas da linguagem natural" à qual se refere Stahl $(2009$, p.72) e pudemos até mesmo fazer brincadeiras em espanhol. Vejamos o excerto 2 abaixo, que foi iniciado por mim um dia antes da aula de espanhol, com o fim de motivar os alunos:

\section{Excerto 2: Provocación del profesor Profesor:}

alumn@:_iQué felicidad! Mañana hay la mejor clase del mundo

Profe: ¿Cuál?

alumn@ $\bar{@}$ :_ila clase de español!

\section{Indicações do Facebook}

12 de septiembre de 2013 a la(s) 21:05

Vista por todos

A ti, alumno 1, alumno 2, alumno 3 y 4 personas más les gusta esto.

Aluno 4: me alegro mucho

12 de septiembre de 2013 a la(s) 21:06

Alumno 3: Vamos hacer perguntas sobre...?

12 de septiembre de 2013 a la(s) 21:34 a través de celular - Me gusta

Profesor: Sobre lo que quieran...la escuela, la rutina, la ciudad, las edades...

12 de septiembre de 2013 a la(s) 21:36 $\cdot$ Me gusta $\cdot 1$

Profesor: Pero, en español, i por favor!!!

12 de septiembre de 2013 a la(s) 21:36 $\cdot$ Me gusta $\cdot 1$

Alumno 3: No, vamos hablar portugues con personas que hablan español!

12 de septiembre de 2013 a la(s) 21:38 a través de celular 
Aluno 3: Akspoakspo

12 de septiembre de 2013 a la(s) 21:38 a través de celular

Profesor: i NOOOOOO!!! Solo español

12 de septiembre de 2013 a la(s) 21:40 $\cdot$ Me gusta $\cdot 1$

Alumno 3: Hahahahaha

12 de septiembre de 2013 a la(s) 21:41 a través de celular

Alumno 5: Yo hablo enpañol muy bien, entónces yo hago las preguntas

12 de septiembre de 2013 a la(s) 22:08 $\cdot$ Ya no me gusta $\cdot 3$

Alumno 5: hahahhaa

No trecho em questão os alunos respondem prontamente à provocação do professor indicando "me gusta" (ferramenta do facebook para demonstrar satisfação) na publicação. Mais adiante um dos alunos utiliza uma fórmula usada frequentemente por mim em aula "me alegro mucho", e no decorrer das manifestações surge um novo tópico e uma nova provocação motivadora do diálogo em espanhol entre professor e alunos: o fato de que na próxima aula os alunos receberiam na sala de aula a visita de alunos intercambistas da Argentina. Havia dito aos alunos em publicação anterior do grupo (excerto 3) que deviam estar preparados para fazer perguntas aos estudantes, e surge uma dúvida de uma das alunas: que tipo de perguntas? Respondo e provoco os alunos dizendo que as perguntas devem ser feitas em espanhol e eles aceitam o convite ao diálogo informal, assumem minha provocação sem estranhamento e passam a responder em espanhol como se estivéssemos em um chat. $\mathrm{O}$ aluno 5 encerra o debate ironicamente dizendo que, como ele sabe muito espanhol, ele fará as perguntas. Há, como podemos ver, uma interação real, descontraída, em que todos estão tentando falar espanhol, o que seria impossível se tratássemos de uma página wiki. Logo, é possível observar por meio dos exemplos que o Facebook funcionou para a construção do conhecimento em espanhol quando foi usado de forma previsível, ou seja, quando as funções de uma rede social foram cumpridas e o ambiente descontraído de uma interação real foi preservado. No momento do diálogo, os alunos não estavam criando uma situação fictícia de sala de aula; estavam agindo a partir de provocações reais utilizando a língua espanhola como meio dessa interação no aqui e agora em que ela se desenvolvia. $\mathrm{O}$ interessante é que a aluna que fala sobre as "perguntas" a serem feitas não está respondendo a essa postagem, senão à postagem anterior (excerto 3). Porém, na interação virtual há certo clima de conversa cruzada que acaba dando certo, porque textualmente 
fomos os envolvidos capazes de reconstruir a espécie par adjacente que se estabeleceu entre as duas publicações ${ }^{5}$ :

Excerto 3: Preguntas a los argentinos

Profesor:

Hola chic@s: Mañana podemos preparar algunas preguntas en español para hacerles a los chicos argentinos...

¿Qué les parece? Tenemos que aprovecharlos...

12 de septiembre de 2013 a la(s) 20:56

- Vista por todos

A alumna 1 y a alumna 2 les gusta esto.

- alumno 3: cuál es su nombre es una...

12 de septiembre de 2013 a la(s) 21:15

Profesor: De acuerdo, pero recuerden que "su" es para usted...

12 de septiembre de 2013 a la(s) 21:16

No próximo excerto a ser examinado, publico um curta-metragem argentino chamado "Sueños", uma interação real. O curta-metragem vem seguido da pergunta que faço: ¿Qué les parece la película? ¿Les gusta?

Vejamos as interações virtuais surgidas a partir da publicação:

\section{Excerto 4: La película}

-Vista por todos

A alumna 1 y alumna 2 les gusta esto.

- alumno 3: La película me gusta, porque da una lección de vida, es muy bonita, el vendedor de sueños es una persona muy inteligente y su abuela también. Por eso me gusta.

- alumna 4: También me gustó la película, porque nos hace pensar y el hombre a pesar de todo parece muy emocionado.

-alumna 5: Me gustó mucho esta película, porque muestra que tenemos que creer en algo y tener fe en que se hará realidad,

-alumna 6: También me gustó la película. Creo como ustedes. Una lección vida. Muy bella historia. El vendedor de sueños es un ejemplo de un ser humano especial.

-alumno 7: A mi tanbiem me gusta la pelicula como nosotros pero me confunde un poco.

- Profesor: ¿Por qué alumno 7?

-alumno 7: yo pienso que fue todo muy confuso.

5 Podemos ver pelas datas das publicações que o excerto 3 foi publicado no grupo antes do excerto 2 . 6 Disponível no youtube em: http://www.youtube.com/watch?v=0udJVDyCoM4. 
-alumno 8: A mí me gusta la película, me passó una mensaje de que soñar jamas es tarde. E que tenemos que soñar a todo el tempo para que podamos alcanzar nuestros objetivos.

-alumna 9: A mi me gusto la película, tambien me paso una mensaje de que soñar hace bien. Me identifiqué con el sentimiento cuando caminó suela por las calles miro las personalidades amargas. Yo esperarava otra respuesta de nene al hombre, pero emocionante. muy lindo!!

- alumno 10: A mi me gusto tambien, es muy buena. Pero no me passó ninguna mensaje. Sólo me gusto.

- alumna 11: A mí tambien, porque paso una mensaje que tenemos que creer, sonar y tener fe, para alcanzar nuestros objetivos.

Aqui novamente podemos perceber que a publicação foi vista por todos os membros e que eles interagem entre si, já que, após o primeiro comentário, os demais quase sempre utilizam a palavras "también" e respondem à pergunta feita por mim acrescentando detalhes não solicitados, ou seja, se o filme passou alguma mensagem. São assim os depoimentos dos alunos 8 e 9, que são rebatidos pelo do aluno 10, que diz que gostou do filme, mas que não lhe passou mensagem alguma. É importante ressaltar que a pergunta feita por mim era simples. Só queria saber se os alunos haviam gostado do curta, em nenhum momento a palavra "mensagem" apareceu em meu texto, porém, como a perspectiva considerada é a dos participantes, os acordos acontecem na própria interação e não na instrução da questão. Os estudantes acharam relevante falar mais coisas do que simplesmente "gosto" ou "não gosto" e tornaram relevante a "mensagem" ou "lição de vida" do filme, nas palavras do aluno 1, de uns para os outros, como se fosse um novo elemento a ser considerado. Tal interação mostra o engajamento dos estudantes à proposta feita pelo professor e ao filme visto, o que está de acordo com a proposta pedagógica do uso do Facebook para a aula de línguas a qual me dispunha. Com base nos excertos selecionados é possível entender que o Facebook possibilitou uma interação real com o uso da língua meta, ao passo que também permitiu que os estudantes, fora da sala de aula, pudessem ter contato com a língua espanhola e contatos entre eles a partir do ambiente virtual, o que também cumpre com os objetivos de uso para a aprendizagem que eu tinha desde o início da proposta.

Contudo, também pude observar ao longo do ano que o êxito das tarefas apresentadas não foi sempre constante, já que nem todas as provocações do professor na comunidade virtual foram aceitas pelos estudantes. Como já mencionado, no mês de setembro a escola em questão recebeu a visita de sete alunos intercambistas da Argentina, que passariam um mês na instituição. Aproveitando o mês de setembro, 
mês de feriados regionais no Rio Grande do Sul, e os laços que unem o sul do Brasil e a Argentina, propus uma aula sobre Martín Fierro, personagem imortal da literatura argentina, que é importante para a construção da figura do gaúcho além das fronteiras do país. Na comunidade español 1 dispus alguns vídeos e informações sobre o livro e o personagem, e os estudantes deveriam pesquisar sobre o tema para discuti-lo e fazer perguntas aos alunos argentinos que haviam acabado de lê-lo em sua escola. Entretanto, diferentemente do que ocorreu nos excertos de interações anteriormente dispostas, dessa vez não houve participação dos estudantes, ainda que pudesse ver que a publicação havia sido vista por todos. Tal episódio, assim como outros semelhantes e não relatados, levou-me a uma reflexão importante: quando a provocação/motivação à tarefa se assemelha às tarefas escolares ela não é aceita, porque passa a ser uma tarefa mais para o estudante do Ensino Médio que não se identifica com ela ou não a identifica como função de uma rede social. Dessa forma, pude perceber que, de acordo com a provocação feita, havia respostas imediatas ou nenhuma resposta, o que demonstra que, como já dito, o Facebook faz parte da vida da maioria dos estudantes com o fim de interagir de maneira previsível para uma rede social, e, quando é usado de forma semelhante à da escola (mais uma tarefa), a comunidade perde sua naturalidade, o que desmotiva os estudantes a engajar-se.

\section{CONSIDERAÇÕES FINAIS}

Após as leituras de textos como Stahl $(2009 ;$ 2011) e Hewitt (2004), é possível refletir sobre a importância dos ambientes virtuais para a construção do conhecimento em comunidades. Em Stahl $(2009 ;$ 2011), uma interação via chat foi capaz de estabelecer o contato entre um grupo virtual, e as negociações entre os membros desse grupo ocorreram visando a resolução de problemas matemáticos. Em Hewitt (2004), uma plataforma de construção de conhecimento, o KBC, despertou o espírito investigativo de estudantes sobre temas da Biologia, com a condução/orientação de um professor em encontros presenciais. Contudo, em ambas as experiências, o que estava em jogo, ainda que permeado pela linguagem, era a construção de conhecimento em matemática e biologia, embora em ambas as experiências não sejam apenas esses os conhecimentos com os quais os participantes tiveram contato, pois puderam, a partir de suas interações, desenvolver melhor sua capacidade de trabalhar em grupo. 
Contudo, quando o que está em jogo é a linguagem, nos colocamos em um lugar bastante diferente, porque as atividades das plataformas ou ambientes virtuais criados para esse fim não podem ser apenas metalinguísticas, visto que a língua precisa de um uso real, de uma materialidade. Por meio dos excertos analisados, podemos notar que o Facebook teve uma aceitação muito grande entre os estudantes, uma vez que não lhes era algo estranho ou obrigado pela escola. Foi uma espécie de ambiente complementar formal/informal que trouxe a vida do aluno para a escola e reforçou os laços de comunidade ao uni-los como grupo virtual com experiências comuns: uma comunidade de jovens que estuda espanhol na escola X.

A cada tarefa proposta no grupo/comunidade do Facebook, os alunos tinham um modelo mínimo e uma espécie de desafio/provocação, aos quais seguiam de acordo com aquilo que era tornado relevante por eles por meio de suas próprias publicações feitas em língua espanhola. No caso de Hewitt (2004), o uso do KBC fazia parte da atividade formal da sala de aula, porém, na aula de língua espanhola, o Facebook foi um complemento à aula com um apelo um pouco diferente: criar situações reais do uso da linguagem. Assim, é possível dizer que os alunos participaram no Facebook com fins de aprendizagem sem sequer talvez terem percebido que o uso da rede tinha também esse objetivo, posto que na maioria das vezes as publicações pareciam fugir da mera obrigação escolar, o que podemos ver pelos detalhes e opções dos estudantes ao publicarem. Da mesma forma, podemos perceber que os alunos valorizaram o recurso por sua adequação ao gênero rede social, fazendo inclusive brincadeiras ao usarem a língua espanhola, fugindo do script tarefa, como podemos ver nos excertos 2 e 3 , no qual os alunos publicaram por livre e espontânea vontade usando a língua meta. Contudo, da mesma forma foi possível perceber que os estudantes estiveram orientados para as atividades do Facebook em alguns momentos, porém não em todos, ou seja, quando o desafio apresentado lhes interessava, participavam, fato que não ocorreu, por exemplo, no chamado com Martín Fierro.

Assim, o Facebook, por meio do estudo realizado, mostrou-se eficiente como recurso de apoio à sala de aula de língua espanhola, devido à sua riqueza de recursos quando falamos da modalidade grupo, muitos deles coincidentes com os já apontados como necessários para a elaboração de plataforma de construção de conhecimento por Stahl (2009). A rede também cumpriu os objetivos do professor, pois dinamizou a aula de língua e foi um ambiente a mais em que os estudantes puderam consultar materiais em língua espanhola e praticar a escrita, interagindo de maneira real em espanhol. Não obstante, é importante para o uso efetivo do Facebook como complemento da sala de aula, que o professor acompanhe as 
publicações e esteja em constante controle de quantos e quais alunos consultaram o grupo, visto que, se não há participação, o grupo perde sua função rede social, o elo entre os membros virtualmente se desfaz, e a rede passa a ser mais uma obrigação da escola, o que, em vez de um ganho, seria um obstáculo para o trabalho com adolescentes do Ensino Médio.

Foi possível perceber, ademais, que os acordos iniciais feitos com o professor no início do ano foram mantidos, mas que as instruções dadas por ele em cada tarefa/ provocação/desafio postado no grupo virtual eram transformadas muitas vezes na hora da interação, que criava novas regras no aqui-e-agora do diálogo virtual. Logo, entendo que o Facebook é uma ferramenta importante para a aprendizagem quando o que está em jogo é a linguagem por ser uma rede com esse fim, ou seja, o uso da linguagem e a prática da interação. A partir dos excertos dispostos e analisados, reitero que o Facebook foi capaz de organizar essa comunidade específica de prática e de construção de conhecimento por ter como base a língua em uso, pressuposto fundamental de uma rede social.

\section{REFERÊNCIAS BIBLIOGRÁFICAS}

ARAGÓN SÁNCHEZ. E. (s/d). Facebook te ha agregado como amigo. Cosmoplitik-Revista Eletrónica al servicio de la comunidad global. Disponível na Intermet em: $<\mathrm{http}: / / \mathrm{www}$. cosmopolitik.com/articulos/Revista_7/Articulos/ErendiraAragonSanchez_foro. pdf $>$. Acesso em: $10 \mathrm{dez} 13$.

COROMINAS, J. (1987). Breve diccionario etimológico de la Lengua Castellana. Madrid: Gredos.

GROS SALVAT, B. (2008). Las comunidades virtuales para la formación permanente del profesorado. REIRE - Revista d'Innovació i Recerca en Educació. 1, nov, pp. 1-10.

HEWITT, J. (2004). An exploration of community in a knowledge forum classroom: An activity system analysis. In: BARAB, S.; KLING, R.; GRA.Y, J (Orgs.), Designing for virtual communities in the service of learning. Cambridge MA: Cambridge University Press, pp. 210-238.

LAVE, J.; WENGER, E. (1991). Situated learning: Legitimate peripheral participation. New York: Cambridge University Press.

POCHON-BERGER, E. (2011). A participant's perspective on tasks: from task instruction, through pre-task planning, to task accomplishment. Novitas-ROYAL (Researcb on Youth and Language), n. 5, pp. 71-90.

RETAMAR, H. J. C. (2011) Site (Página wiki) de trabalbo da disciplina de Língua espanbola. Disponível em: http://110yelcastellano.pbworks.com. Acesso em: 15 out. 2013. 
RETAMAR, H. J. C. (2013). Língua(s), Espaço(s) na Escola e Plurilinguismo: um desafio para este milênio. VI Encontro Internacional de Investigadores de Políticas Linguísticas. Porto Alegre: UFRGS, pp. 189-194.

RIEL, M.; POLIN, L. (2004). Models of community learning and online learning in communities. In: BARAB, S.; KLING, R.; GRAY, J. (Orgs.). Designing for virtual communities in the service of learning. Cambridge: Cambridge University Press, pp. 16-50.

RODRÍGUEZ ILLERA, J. L. (2007). Como as comunidades virtuais de prática e de aprendizagem podem transformar a nossa concepção de educação. Sísifo - revista de ciências da educação. n.3, mai/ago, pp. 117-124.

SCHLATTER, M.; BULLA, G. S.; GARGIULO, H. (2013). O CEPI como ação de política linguística para o intercâmbio acadêmico. VI Encontro Internacional de Investigadores de Políticas Linguísticas. Porto Alegre: UFRGS, pp. 107-112.

STAHL, G. (2009). From Individual representations to group cognition. STAHL, G. (Org.), Studying virtual Matb teams. New York: Springer, pp. 57-82.

STAHL, G. (2011). How a virtual math team structured its problem solving. In: the international conference on Computer-Supported Collaborative Learning. Hong Kong, China. Disponível em <http://GerryStahl.net/pub/cscl2011stahl.pdf>， <shttp:// youtube/0Dg02YQCQIE $>$, pp. 256-263, 2011. Acesso em: 12 set 2013

Recebido: 23/05/2016

Aceito: 06/03/2017 